\title{
A Brief Analysis of Opportunities and Challenges for Accounting Personnel in the Big Data Era
}

\author{
Xia Jing \\ Finance Department, Wuhan University of Textile, \\ Wuhan, P.R.China, 430200 \\ E-mail: callidora2015@163.com
}

\begin{abstract}
This paper, mainly from the background of big data, the conception and characteristics of big data, combined with the reformed direction of financial information system in the era of big data, puts forward the strategic significance of accounting personnel's positioning transition and functional promotion, and emphasizes the following three research directions, that is, Great data of financial data, accounting standardization and the wisdom of the investment decision. Finally, this paper conclude that the solution of assisting businesses to take advantage of the financial management of big data is a worth pondering question. Meanwhile, financial officers should keep with the times to enhance to help companies maximize value through their professional skills, integrated management capacity and the security of data storage and analysis.
\end{abstract}

Key words_Big data; Accounting personnel;
Opportunities; Challenges

In China, the accounting computerization has gained popularity in recent years. Most enterprises have got rid of the tedious manual bookkeeping and stepped into the informatization palace. Big data era and financial informatization will be full of new life. A lot of work having difficulty in information collection, processing and analysis, such as enterprises' investment decisions and comprehensive budget management, etc. will no longer be difficult problems; the financial information system will better help enterprises realize management promotion in enterprise investment decisions, accounting management specification, comprehensive budget and cost reduction, etc.

\section{INTRODUCTION}

Internationally, as early as in 2008, Nature launched a specified issue Big data. It introduced and analyzed the potential values and challenges of big data systematically from the current research situation of multiple disciplines, since then big data started arising a wide and heated discussion among academia. In February 2011, Science launched a special issue "Dealing with data", having a discussion in view of big data problems in the scientific research and elaboration in terms of the importance of Big data to scientific research. In June, 2011, McKinsey published a detailed report on big data: "Big data: The next frontier for innovation, competition, and productivity.” This report stated in detail from aspects of

\author{
Zhou Wanyi \\ Finance Department, Wuhan University of Textile, \\ Wuhan, P.R.China, 430200 \\ E-mail:305093906@qq.com
}

the background of big data, key technology and applied scale, etc. Then in January, 2012, big data became one of the themes of Davos world economic forum and released a report: "Big data, big impact: new Possibilities for international development." The report discussed, under the current society, how to utilize the huge amount of data to serve and improve the society. Since then, big data attracted attention of every government. In March, 2012, American Obama government invested over 200 million dollars and started the "big data development plan" formally, which planned to do researches on how to make breakthroughs in scientific research, environment and bio-medicine, etc. by utilizing big data technology. This plan is regarded as another major measures in information technology field by American government after "the information highway plan”.

In China, research on big data is a little slow. In 2012, the article of Big Data Management: Conception, Technology and Challenges written by Meng Xiaofeng and Ci Xiang analyzed the basic conception of big data, elaborated the basic frame of big data and summarized the challenges in the era of big data. In 2012, Chen Ruming published Challenges, Values and Corresponding Strategies in the Era of Big Data, which analyzed the values, challenges of big data and solutions to big data, and pointed out that in the era of big data, at the same time of revealing data value, great importance should be attached to data security protection. Subsequently, in 2014, Chen Yuming published A Discussion of Group Finance-sharing Problem in the Big Data Era, which elaborated the necessity for group enterprises to establish a finance-sharing center in the era of big data and pointed out that the era of big data will cause a reform of enterprise financial work. In addition, Jiang Kanming, Zhang Xiaolei and Fan Xiaoming, etc. analyzed the influences on financial management work caused by big data era, thinking that the era of big data will bring more change to financial management work.

\section{THE CONCEPTION AND CHARACTERISTICS OF BIg DATA}

At present, big data topic has aroused a wide discussion among all circles. Every research institution and corporation have defined the big data, among which, Wiki defines big data : its involved data quantity is so huge that can not go through current mainstream software tools to capture, manage and sort out information which 
can help the corporation make a decision in a more positive purpose within a reasonable time. While the research consultancy institution Gartner defines that "big data" needs to have a new processing model and then it can have huge, high-growth rate and high variety information assets with more powerful decision-making force, insight-discovery and process optimization abilities. No matter which kind of definition, both points out that big data is different from VLDB (very large database) and XLDB (extremely large database), and the current mainstream software has not handled it effectively, new technology is needed to be used to search information and realize its value.

As to the characteristics of big data, IBM Corporation uses $3 \mathrm{v}$ to summary big data, namely, volume, velocity and variety, which is more representative. Specifically, volume refers to that the amount of data is extremely huge and it still continues to increase; velocity refers to that the speed of the needed disposal is fast and the response time is short; variety refers to various types of data, including structured data, semi-structured data, even unstructured data (distinguishing the conception of Big data from large data with huge amounts in this way); while based on $3 \mathrm{v}$, the international data corporation IDC puts forward value, namely, $4 \mathrm{v}$. Value refers to the low density. Strategic significance of Big data is not only the data itself, but also in mining and professional handling of the data. Facing the challenge of large data, every accountant must re-examine its own role in the financial restructuring.

\section{THE CHANGE DiRECTION OF FINANCIAL INFORMATION SYSTEM IN THE ERA OF BIG DATA}

\section{A. Realizing the actual big datamation of financial data}

Accounting computerization releases accounting personnel from tedious manual bookkeeping. The accounting personnel do not pass, process and summarize data by hand, but "translate" the financial original documents into financial data and record it in the database. The data will be processed again in the database. Undoubtedly, accounting computerization can bring many conveniences to accounting personnel. But the database storage method determines that the financial data in the database is only the structured data in the financial data sea, and for the unstructured financial data, the database is unable. In the present financial system, we can only refer to part financial data which is translated from the original documents. If one wants to see the source of financial data, the original documents must be referred to. And in the era of big data, the original documents also must realize "datamation". We are free to draw on and use the data in the "datamation" original documents.

B. Guaranteeing financial accounting standards and realizing quick finance

Literally, big data often tends to make people attach importance to data size but ignore the connection among data. Under double-entry bookkeeping, every document has its creditor and borrower, which makes the accounting subjects, account accounts and accounting statements closely connected. The emergence of accounting computerization avoids the risk of unfairness between creditor and borrower by manual bookkeeping, but it is difficult to make a difference in accounting subjects' applying standards and in the quality inspection of accounting statements data. For small and medium-sized enterprises, it is relatively easy to correct the data error in the accounting statements later, but for the merged group enterprises with a lot of financial statements, accounting irregularities will become the financial personnel's nightmare. And in the era of big data, enterprise accounting standards and the connection among financial statements will be brought into the financial system as the checking norms of financial data. Real-time control of the implementation of enterprise accountants' accounting standards and the quality of the statements' data will be carried out, so that it can realize the smooth implementation of the enterprise monthly statements' combination as well as the actual quick finance.

\section{Providing investment decision support and realizing wise decision}

In the big context of increasingly developed scientific technology and increasingly fierce market competition, enterprises can not still rely on investment-driven and scale-expanded developing method to realize the development of the enterprise. Enterprises need to establish and improve scientific decision-making evaluation system to guide enterprises to invest their capitals in a project with higher efficiency and more profits. But an effective decision-making evaluation system must have a mature and reliable data to provide support for decision making. The financial information system in the era of big data can extend to the periphery of the enterprise, provide relevant risks and expected profits etc. of the similar projects in the market, and within the enterprise, match total amount of investment calculation model with the result of project optional sequencing, predict the funding gap, design financing plan and form an integrated investment decision-making evaluation system. With the further maturation of big data development, the analysis of the external market risks for the future enterprise investment decision will be included in the financial information system to realize the wise investment of financial personnel.

\section{OPPORTUNITIES AND CHALLENGES OF FINANCIAL PERSONNEL}

\section{A.Protecting the data security}

In the fierce competition of the big data flush, enterprise information management faces double challenges of internal management and external attacks. It can not 
prevent data mining, application and sharing, as well as prevent information from being damaged, tampered or disclosed. When collecting and using the data, accounting personnel should strictly obey legal review and supervision and have a clear idea of the permission and scale of data collection and application. They should verify the system account privileges at regular intervals to prevent that improper operation leads to enterprise financial information leakage and ensuring the security of data storage and analysis.

\section{B. Promoting professional skills}

The accounting personnel in the era of big data will be data managers, analyzers even technical supporters. They must promote self-learning awareness and the cognition of new knowledge, cultivate the sensitivity of data collection, analysis and processing and set up big data thinking pattern. Through the computer platform, they can carry out multi-angel and comprehensive data application training, enhance and innovate the skill of processing data and establishing models. Self-choosing Internet training resources according to their own characteristics, at the same time, they should strengthen cooperative learning to improve training efficiency, as well as check and test the training results in real time, so as to ensure practical promotion of their professional quality and business skills.

\section{Capabilities on Training comprehensive management}

If one can not have the insight into valuable information from the big data and make response, it is meaningless to own many methodical data. Accounting personnel need a real transformation of their skills: becoming a controller of data, cultivating the soft skills, such as perspective thinking, imagination and creation, etc., learning to transfer and invoke the potential of data. Instead of only focusing on the capture, integration and analysis of data, they should put their eyes into achieving intelligence, exploration and taking exact action. The cultivation and establishment of this comprehensive ability must be carried out. Enterprise internal data exchange and sharing also need the accounting personnel to play their wisdom to break the barriers hindering the development of the enterprise and use effective data management and integrated thinking to cooperate and communicate with other departments more closely, helping to maximize the data value.

\section{V.CONCLUSION}

The baptism of the big data wave is a double-edged sword to accounting personnel, which have strategic significance for their positioning transition and functional promotion; on the contrary, if accounting personnel can not keep pace with the times, undoubtedly, they will gradually face a marginalized situation. Only by thinking about the direction of the future development and chasing after the wave tide in a more proactive attitude can they keep pace with the times and have a powerful and sustainable development of the future.

\section{REFERENCES}

[1] Albert - Laszlo Bara Brazil, Outbreak: On new thinking foreseeable future in Big Data era [M] Beijing: China Renmin University Press, 2012.

[2] Bill •Franks, large data management [M] Beijing: People’s Posts and Telecommunications Press, 2013.

[3] Zhang Huide, Chen Wenxin, On "three-dimensional” of new big data era accounting information to [J] China Accounting newspaper, 2013.

[4] Wu Hequan. On Opportunities and Challenges in Big Data era [J]. Qiushi magazine, 2013.

[5]Nature. Big data

[EB/OL ] .[2012-10-12].http://www.natrue.com/news/specials/bigdata /imdex.html. 